\title{
High Phosphatidylcholine Hydroperoxide Level in Plasma of Guinea Pigs with Low and Excess Supplementation of Ascorbic Acid
}

\author{
Mikio Kinoshita, Kenshiro Fujimoto, and Teruo Miyazawa* \\ Department of Applied Biological Chemistry, Tohoku University, \\ Tsutsumidori Amamiyamachi 1-1, Sendai 981, Japan
}

(Received June 7, 1995)

Summary Graded amounts (0, 50, 500 and 5,000 mg/liter) of ascorbic acid (AsA) were given in drinking water to guinea pigs for 21 days to prepare AsA-deficient, low-AsA, moderate-AsA and excess-AsA animals, and the plasma phospholipid hydroperoxide level and lipid concentration were quantitatively determined to investigate the antioxidant effect of AsA in vivo. Phosphatidylcholine hydroperoxide $(\mathrm{PCOOH})$ was a predominant phospholipid hydroperoxide present in the plasma, and the $\mathrm{PCOOH}$ concentration was significantly higher in AsA-deficient, lowAsA and excess-AsA animals $(80.4 \mathrm{nM}, 54.8 \mathrm{nM}$ and $42.2 \mathrm{nM}$, respectively) as compared with that in moderate-AsA animals (27.2 nM). Hyperlipidemic plasma characterized as high cholesterol and high triacylglycerol concentrations was confirmed in AsA-deficient animals. Molar ratios of plasma AsA and $\alpha$-tocopherol against $10^{4}$ moles of phospholipids were significantly lower in AsA-deficient and low-AsA animals (0.6-2.1 and 5.5-8.5, respectively) than in moderate-AsA and excess-AsA animals (14.2-18.0 and 11.2-11.9, respectively). In plasma, a high correlation coefficient $(r=0.979)$ was observed between PCOOH and AsA for which there was optimum AsA level to keep the low $\mathrm{PCOOH}$ and such correlation was stronger than that $(r=0.558)$ observed with $\alpha$-tocopherol. The results indicated that AsA has an important function to control the phospholipid hydroperoxide level in plasma and that moderate supplementation of AsA is required to reveal its optimal antioxidant effect in vivo. The present study also showed that AsA-deficiency especially invites an increase in plasma $\mathrm{PCOOH}$ together with a hyperlipidemic state which are risk factors in developing atherogenesis.

Key Words ascorbic acid, $\alpha$-tocopherol, phosphatidylcholine hydroperoxide, plasma lipids, hyperlipidemia, guinea pig

\footnotetext{
* To whom correspondence should be addressed.
} 
Ascorbic acid (AsA) is known to act as antioxidant scavenging singlet molecular oxygen $(1)$, superoxide and hydroxyl radical $(2,3)$ which are reactive oxygen species causing membrane lipid peroxidation. In in vitro systems, regeneration with AsA of a lipophilic antioxidant $\alpha$-tocopherol from tocopheryl radical has also been suggested with respect to its antioxidative mechanism (4). In the animal experiments, feeding of AsA-deficient diet (below $0.1 \mathrm{mg} \mathrm{AsA} / \mathrm{kg}$ diet) causes an increase in the level of thiobarbituric acid-reactive substances (TBARS) as a tentative indication of lipid peroxides in the plasma of guinea pigs (5) and in the livers and brains of rats (6). With AsA-deficiency, the plasma $\alpha$-tocopherol level is decreased in rats (6). On the other hand, AsA has been known to act as prooxidant when AsA chelates with iron reportedly led to the production of peroxidative $\mathrm{Fe}(\mathrm{II})$ (7). In rats, supplementation of excess AsA (1,500 mg/kg diet) brings about a high incidence of erythrocyte hemolysis accompanied by an increase in liver TBARS and a decrease in plasma tocopherol (8). Therefore, it is expected that there is some optimum level for dietary AsA, by which AsA can act as an effective antioxidant but not as a prooxidant in tissue organelles in vivo. In human plasma, high accumulation of phosphatidylcholine hydroperoxide as a primary oxidation product of phosphatidylcholine located at the surface of lipoprotein particles has been found in patients with hyperlipidemia (9). The enhanced phosphatidylcholine hydroperoxide level in plasma should directly reflect the formation of oxidized lipoprotein particles that are a possible causative agent for developing atherogenesis (10). As the hyperlipidemic state has been observed in the plasma of AsA-deficient guinea pigs (11), its contribution in modifying the plasma lipid hydroperoxide level is also interesting. In the present study, graded amounts of AsA were given to guinea pigs, and the plasma phosphatidylcholine hydroperoxide level and lipid profile were investigated to estimate the optimum amount of AsA which can prevent both the lipid hydroperoxide accumulation and normalize the hyperlipidemic state of the plasma.

\section{MATERIALS AND METHODS}

Animals and diets. Hartley strain male guinea pigs ( 3 weeks old, $n=20$ ) were purchased from Agricultural Cooperative Association for Laboratory Animals (Hamamatsu). The animals were submitted to prefeeding to a body weight of 410 $\mathrm{g}$ with a commercial pellet rations (guinea pigs diet GM-1, containing 1,500 $\mathrm{mg}$ vitamin $\mathrm{C} / \mathrm{kg}$ and $50 \mathrm{mg}$ vitamin $\mathrm{E} / \mathrm{kg}$, Funabashi Farm Co., Funabashi). Each animal was kept in a wire-bottomed stainless-steel cage, and water was supplied $a d$ libitum. In the feeding experiment, the AsA intake was adjusted by drinking water to prepare AsA-deficient ( $0 \mathrm{mg} /$ liter, group A), low-AsA ( $50 \mathrm{mg} /$ liter, group B), moderate-AsA $(500 \mathrm{mg} /$ liter, group C) and excess-AsA $(5,000 \mathrm{mg} /$ liter, group D) animals, respectively. The animals of all groups were maintained on an AsA-free diet (contained $50 \mathrm{mg}$ vitamin $\mathrm{E} / \mathrm{kg}$; Oriental Yeast Co., Tokyo) for 22 days of the feeding period. On day 22 of feeding, the animals were fasted overnight and 
anesthetized with diethylether. Heparinized blood was withdrawn by heart puncture and was centrifuged at low speed $(1,000 \times g)$ at $4{ }^{\circ} \mathrm{C}$ for $10 \mathrm{~min}$ to separate the plasma.

Plasma lipid analyses. Plasma total-cholesterol (TC), free-cholesterol (FC), triacylglycerol (TG) and phospholipids (PL) were determined using the cholesterol-E-test, free cholesterol-E-test, triglyceride-E-test and phospholipid-C-test (Wako Pure Chemical Co., Osaka), respectively. Plasma AsA was measured by the dinitrophenylhydrazine method (12). Plasma $\alpha$-tocopherol was determined by high-performance liquid chromatography (13). Fatty acid composition of plasma lipids was analyzed as methylesters (14) using a Shimadzu GC-8A gas chromatograph.

Lipid hydroperoxide assay. Phosphatidylcholine hydroperoxide $(\mathrm{PCOOH})$ present in plasma was determined by chemiluminescence-high performance liquid chromatography (CL-HPLC) as has been reported by Miyazawa et al. $(15,16)$.

Statistical analysis. The data are expressed as mean values and standard deviations (SD). All data were analyzed using ANOVA and Student's $t$-test. The coefficient of correlation between PCOOH and AsA levels in plasma was compared with the regression curve of secondary degree.

\section{RESULTS}

\section{Body weight gain}

Figure 1 shows the weight gain of guinea pigs during the experimental period (22 days) given graded doses of AsA. AsA-deficient animals (group A) showed the smallest weight gain among the four groups, and apparent weight loss was observed

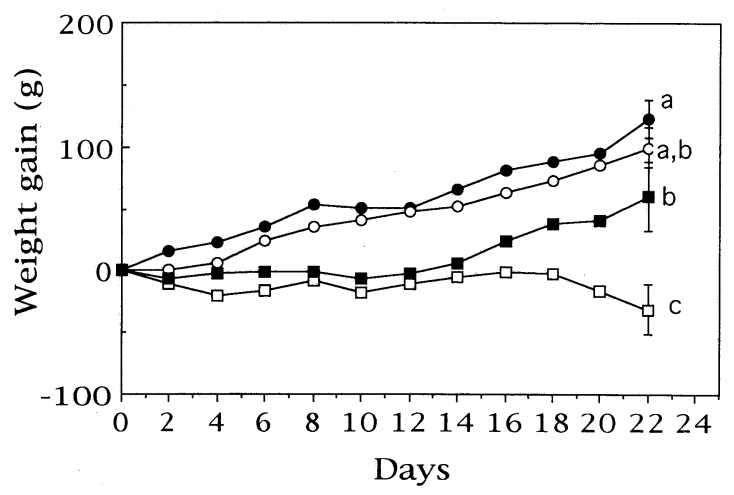

Fig. 1. Weight gains of guinea pigs received graded doses of ascorbic acid (AsA). The animals fed with AsA-deficient diet were supplemented with AsA by drinking water in the following doses for 22 days: $\square$, AsA $0 \mathrm{mg} /$ liter (AsA-deficient); ๑, AsA $50 \mathrm{mg} /$ liter (low-AsA); $\bigcirc$, AsA $500 \mathrm{mg} /$ liter (moderate-AsA); $\mathbf{\square}$, AsA $5,000 \mathrm{mg} /$ liter (excess-AsA). ${ }^{\mathrm{a}, \mathrm{b}, \mathrm{c}}$ Values with different superscript letters are significantly different at $p<0.05$. Vertical bars at day 22 represent SD of means. 
in group A animals after the 18th day due to the lack of appetite, and at the 22nd day AsA-deficient animals (group A) revealed typical scorbutic symptoms. Among the AsA-supplemented animals (groups B, C and D), the weight gain of excess-AsA animals (group D) was smaller than that of moderate-AsA animals (group B) and of low-AsA animals (group C). No significant difference was observed between the moderated-AsA animals and the low-AsA animals.

\section{Plasma AsA and $\alpha$-tocopherol}

The AsA concentration in the plasma of AsA-deficient animals (group A) and of low-AsA animals (groups B) were significantly lower than that of moderatedAsA animals (group C) and of excess-AsA animals (group D) (Table 1). The lowest AsA concentration was observed in the plasma of AsA-deficient animals (group A). No difference was from 0.6 to 2.1 observed between the moderate-AsA animals and the excess-AsA animals. The molar ratio of AsA against $10^{4}$ moles of plasma phospholipids was in AsA-deficient and low-AsA animals while in moderated-AsA and excess-AsA animals the molar ratio was 14.2-18.0.

The $\alpha$-tocopherol concentration, expressed as $\mu \mathrm{g} / \mathrm{ml}$ plasma, in AsA-deficient animals (group A) and in low-AsA animals (group B) was somewhat higher (0.4$0.5 \mu \mathrm{g} / \mathrm{ml}$ ) than that in moderate-AsA animals (group C) and excess-AsA animals (group D) $(0.3 \mu \mathrm{g} / \mathrm{ml})$ (Table 1), while the molar ratio of $\alpha$-tocopherol against $10^{4}$ moles of plasma phospholipids was significantly lower in AsA-deficient animals and low-AsA animals (5.5-8.5) than that in moderate-AsA animals and excess-AsA animals (11.2-11.9). The plasma $\alpha$-tocopherol level of excess-AsA animals and of moderate-AsA animals was almost the same.

As shown in Fig. 2, a biphasic relationship was seen between plasma AsA and $\alpha$-tocopherol levels; these levels were inversely proportional to each other when compared by units of $\mu \mathrm{g} / \mathrm{ml}$ plasma (Fig. 2-A), but were rather proportional when compared by the units of $\mathrm{mol} / 10^{4} \mathrm{~mol}$ plasma phospholipids (Fig. 2-B).

Table 1. Ascorbic acid and $\alpha$-tocopherol levels in the plasma of guinea pigs given graded doses of ascorbic acid.

\begin{tabular}{lcclcc}
\hline \multirow{2}{*}{ Group } & \multicolumn{2}{c}{ Ascorbic acid } & & \multicolumn{2}{c}{$\alpha$-Tocopherol } \\
\cline { 2 - 3 } \cline { 5 - 6 } & $\mu \mathrm{g} / \mathrm{ml}$ & $\mathrm{mol} / 10^{4} \mathrm{~mol} \mathrm{PL}$ & & $\mu \mathrm{g} / \mathrm{ml}$ & $\mathrm{mol} / 10^{4} \mathrm{~mol} \mathrm{PL}$ \\
\hline A (AsA-deficient) & $1.1 \pm 0.3^{\mathrm{a}}$ & $0.6 \pm 0.2^{\mathrm{a}}$ & & $0.5 \pm 0.1^{\mathrm{b}}$ & $5.5 \pm 1.3^{\mathrm{a}}$ \\
B (low-AsA) & $1.9 \pm 0.4^{\mathrm{b}}$ & $2.1 \pm 0.4^{\mathrm{b}}$ & & $0.4 \pm 0.1^{\mathrm{a}, \mathrm{b}}$ & $8.5 \pm 1.7^{\mathrm{a}, \mathrm{b}}$ \\
C (moderate-AsA) & $8.4 \pm 1.8^{\mathrm{c}}$ & $14.2 \pm 3.9^{\mathrm{c}}$ & & $0.3 \pm 0.0^{\mathrm{a}}$ & $11.2 \pm 1.5^{\mathrm{b}}$ \\
D (excess-AsA) & $8.9 \pm 1.0^{\mathrm{c}}$ & $18.0 \pm 2.0^{\mathrm{c}}$ & & $0.3 \pm 0.0^{\mathrm{a}}$ & $11.9 \pm 2.7^{\mathrm{b}}$ \\
\hline
\end{tabular}

Values are $\mathrm{M} \pm \mathrm{SD}(n=5)$. ${ }^{\mathrm{a}, \mathrm{b}, \mathrm{c}}$ Values with different superscript letters in a column are significantly different $(p<0.05)$. The animals fed ascorbic acid (AsA)-deficient diet were supplemented with AsA by drinking water in the following dose: A, AsA 0 $\mathrm{mg} /$ liter; B, AsA $50 \mathrm{mg} /$ liter; C, AsA $500 \mathrm{mg} /$ liter; and D, AsA $5,000 \mathrm{mg} /$ liter. PL, phospholipids. 

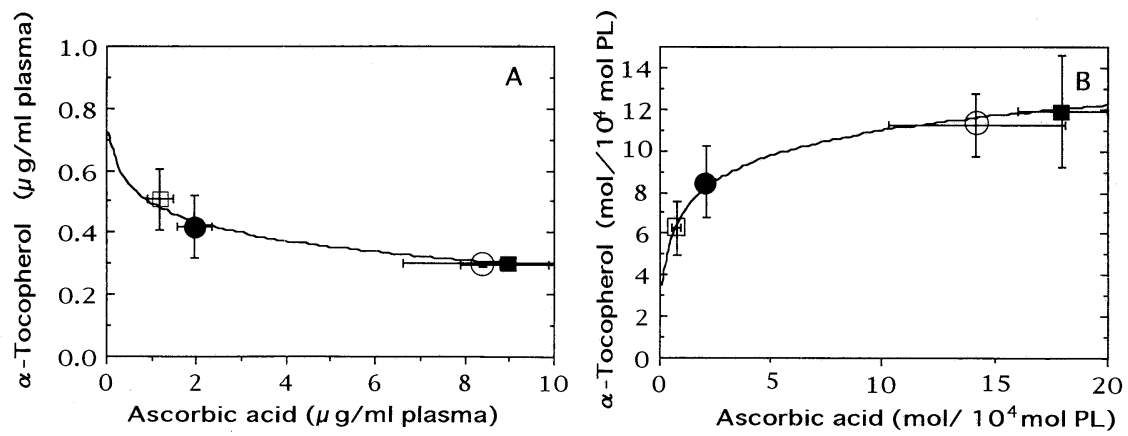

Fig. 2. Relationship between ascorbic acid (AsA) and $\alpha$-tocopherol levels in the plasma of guinea pigs received graded amounts of AsA. A, relationship in $\mu \mathrm{g} / \mathrm{ml}$ plasma; B, relationship in $\mathrm{mol} / 10^{4} \mathrm{~mol} \mathrm{PL}$ (phospholipids). Abbreviations are the same as those given in Fig. 1. Bars represent SD of means.
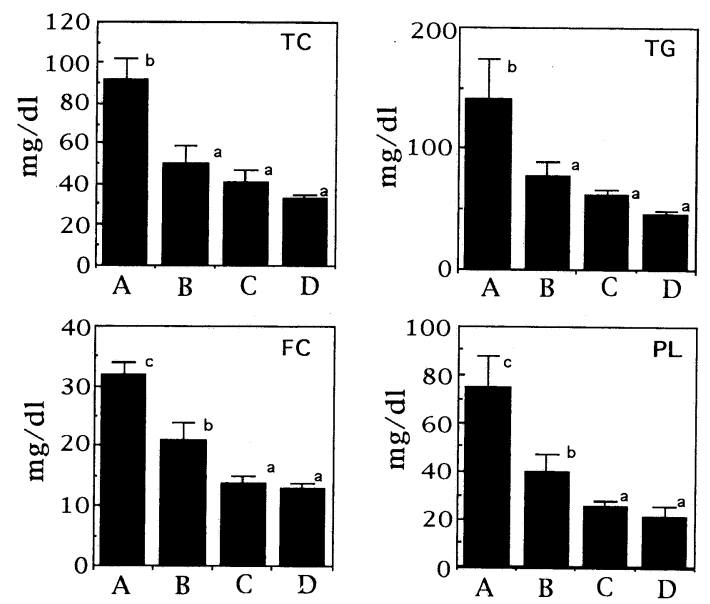

Fig. 3. Plasma lipid profile of guinea pigs received graded doses of ascorbic acid (AsA). The animals were maintained on AsA-deficient diet and supplemented with AsA by drinking water in the following doses for 22 days. A, AsA $0 \mathrm{mg} /$ liter (AsA-deficient); B, AsA $50 \mathrm{mg} /$ liter (low-AsA); C, AsA $500 \mathrm{mg} / \mathrm{liter}$ (moderate-AsA); D, AsA 5,000 mg/liter (excess-AsA). TC, total-cholesterol; FC, free cholesterol; TG, triacylglycerol; PL, phospholipids. Values are $\mathbf{M} \pm \mathrm{SD}$ $(n=5){ }^{\text {a, b,c }}$ Values with different superscript letters are significantly different at $p<0.05$.

\section{Plasma lipid profile}

Figure 3 shows the plasma lipid concentration of guinea pigs given graded amounts of AsA for 22 days. In the plasma of AsA-deficient animals (group A), the total cholesterol, free cholesterol, triacylglycerol and phospholipid concentrations were higher than in any of the other three groups. The plasma cholesterol and 
Table 2. Fatty acid compositions of plasma total lipids of guinea pigs given graded doses of ascorbic acid (AsA).

\begin{tabular}{lcccc}
\hline \multirow{4}{*}{ Fatty acid } & \multicolumn{4}{c}{ Group } \\
\cline { 2 - 5 } & $\begin{array}{c}\text { AsA 0 mg/liter } \\
\text { (AsA-deficient) }\end{array}$ & $\begin{array}{c}\text { AsA 50 mg/liter } \\
\text { (low-AsA) }\end{array}$ & $\begin{array}{c}\text { AsA 500 mg/liter } \\
\text { (moderate-AsA) }\end{array}$ & $\begin{array}{c}\text { AsA 5,000 mg/liter } \\
\text { (excess-AsA) }\end{array}$ \\
\hline & \multicolumn{4}{c}{ weight \% } \\
$14: 0$ & $1.4 \pm 0.3$ & $0.8 \pm 0.1$ & $0.7 \pm 0.1$ & $0.9 \pm 0.2$ \\
$16: 0$ & $18.3 \pm 0.3$ & $20.0 \pm 0.5$ & $17.6 \pm 0.8$ & $22.6 \pm 1.3$ \\
$16: 1 n 7$ & $1.6 \pm 0.5$ & $1.1 \pm 0.1$ & $1.1 \pm 0.1$ & $0.6 \pm 0.4$ \\
$18: 0$ & $10.1 \pm 0.3$ & $10.4 \pm 0.4$ & $11.2 \pm 0.3$ & $11.1 \pm 0.1$ \\
$18: 1 n 9$ & $16.1 \pm 1.2$ & $19.1 \pm 0.3$ & $16.4 \pm 0.4$ & $18.3 \pm 0.3$ \\
$18: 2 n 6$ & $42.1 \pm 3.0$ & $39.4 \pm 0.9$ & $41.7 \pm 0.2$ & $39.4 \pm 0.9$ \\
$20: 4 n 6$ & $4.9 \pm 2.1$ & $6.1 \pm 0.4$ & $5.8 \pm 0.5$ & $3.3 \pm 1.4$ \\
$22: 5 n 3$ & $0.5 \pm 0.1^{\mathrm{a}}$ & $0.2 \pm 0.1^{\mathrm{a}}$ & $0.1 \pm 0.0^{\mathrm{a}}$ & $2.9 \pm 0.7^{\mathrm{b}}$ \\
$22: 6 n 3$ & $2.1 \pm 0.3^{\mathrm{b}}$ & $1.0 \pm 0.1^{\mathrm{a}}$ & $2.8 \pm 0.5^{\mathrm{b}}$ & $0.8 \pm 0.6^{\mathrm{a}}$ \\
\hline
\end{tabular}

Values are $\mathrm{M} \pm \mathrm{SD}(n=5)$. ${ }^{\mathrm{a}, \mathrm{b}}$ Values with different superscript letters of each fatty acid are significantly different $(p<0.05)$ among the animal groups.

triacylglycerol levels of AsA-deficient animals (group A) were two times and the phospholipid concentration was three times higher than those of the moderate-AsA animals (group C). A slight but significant increase was also observed in the plasma free cholesterol and phospholipid concentrations in low-AsA animals (group B) as compared with those of moderate-AsA (group C) and excess-AsA (group D) animals. No difference was observed in the plasma lipid concentrations between the moderate-AsA animals and the excess-AsA animals.

The major constituent fatty acids of the plasma total lipids of guinea pigs were linoleic (39.4-42.1\%), palmitic (17.6-22.6\%), oleic (16.1-19.1\%) and stearic (10.1-11.2\%) acids (Table 2). The compositional proportion of such major fatty acids was not changed even after the change of AsA intake. A little change was observed in the proportions of 22:5n-3 (docosapentaenoic acid, DPA) and 22:6 n-3 (docosahexaenoic acid, DHA), while 20:5n-3 (eicosapentaenoic acid, EPA) was not detected in the plasma. No significant difference was observed in the fatty acid composition of plasma phosphatidylcholine among the four animal groups (Table 3).

\section{Plasma PCOOH}

In the plasma of guinea pigs, $\mathrm{PCOOH}$ was a predominant phospholipid hydroperoxide. Among the four animal groups that received graded doses of AsA, the highest $\mathrm{PCOOH}$ concentration $(80.4 \mathrm{nM})$ was observed in the plasma of AsA-deficient animals (group A) (Table 4). The plasma PCOOH level of the moderate-AsA animals (group C; $27.2 \mathrm{nM}$ ) was lowest among the four groups, and that of excess-AsA animals (group D; $42.2 \mathrm{~nm}$ ) and low-AsA animals (group B; $54.8 \mathrm{nM}$ ) was significantly higher than the moderate-AsA animals. The molar ratio 
Table 3. Fatty acid composition of plasma phosphatidylcholine of guinea pigs given graded doses of ascorbic acid (AsA).

\begin{tabular}{lrrrr}
\hline & \multicolumn{4}{c}{ Group } \\
\cline { 2 - 5 } Fatty acid & $\begin{array}{c}\text { AsA 0 mg/liter } \\
\text { (AsA-deficient) }\end{array}$ & $\begin{array}{c}\text { AsA 50 mg/liter } \\
\text { (low-AsA) }\end{array}$ & $\begin{array}{c}\text { AsA 500 mg/liter } \\
\text { (moderate-AsA) }\end{array}$ & $\begin{array}{c}\text { AsA 5,000 mg/liter } \\
\text { (excess-AsA) }\end{array}$ \\
\hline & \multicolumn{4}{c}{ Weight \% } \\
$14: 0$ & $2.1 \pm 0.5$ & $4.2 \pm 1.5$ & $1.6 \pm 0.4$ & $4.5 \pm 1.1$ \\
$16: 0$ & $18.7 \pm 0.4$ & $18.9 \pm 0.6$ & $19.3 \pm 1.1$ & $18.0 \pm 0.7$ \\
$16: 1 n 7$ & $1.4 \pm 0.1$ & $2.0 \pm 0.1$ & $1.2 \pm 0.1$ & $1.2 \pm 0.2$ \\
$18: 0$ & $36.5 \pm 1.3$ & $35.1 \pm 0.8$ & $36.1 \pm 1.6$ & $35.8 \pm 2.0$ \\
$18: 1 n 9$ & $9.9 \pm 1.2$ & $8.8 \pm 0.1$ & $10.9 \pm 0.7$ & $8.5 \pm 1.0$ \\
$18: 2 n 6$ & $28.6 \pm 1.0$ & $28.1 \pm 1.7$ & $26.9 \pm 2.9$ & $28.5 \pm 1.4$ \\
$20: 4 n 6$ & $1.3 \pm 0.1$ & $1.2 \pm 0.1$ & $1.9 \pm 0.4$ & $1.7 \pm 0.3$ \\
$22: 5 n 3$ & $0.5 \pm 0.1$ & $0.3 \pm 0.1$ & $0.9 \pm 0.5$ & $1.0 \pm 0.5$ \\
$22: 6 n 3$ & $1.0 \pm 0.3$ & $1.5 \pm 0.4$ & $1.2 \pm 0.3$ & $1.0 \pm 0.2$ \\
\hline
\end{tabular}

Values are $\mathrm{M} \pm \mathrm{SD}(n=5)$.

Table 4. Phospholipid hydroperoxides in plasma and livers of guinea pigs given graded doses of ascorbic acid.

\begin{tabular}{|c|c|c|c|c|c|c|}
\hline \multirow{3}{*}{ Group } & \multirow{2}{*}{\multicolumn{2}{|c|}{$\begin{array}{c}\text { Plasma } \\
\mathrm{PCOOH}\end{array}$}} & \multicolumn{4}{|c|}{ Livers } \\
\hline & & & \multicolumn{2}{|c|}{$\mathrm{PCOOH}$} & \multicolumn{2}{|c|}{ PEOOH } \\
\hline & $\mathrm{nM}$ & $\begin{array}{l}\mathrm{mol} / 10^{5} \\
\mathrm{~mol} \mathrm{PL}\end{array}$ & $\mathrm{nmol} / \mathrm{g}$ & $\begin{array}{c}\mathrm{mol} / 10^{5} \\
\mathrm{~mol}\end{array}$ & $\mathrm{nmol} / \mathrm{g}$ & $\begin{array}{c}\mathrm{mol} / 10^{5} \\
\mathrm{~mol}\end{array}$ \\
\hline A (AsA-deficient) & $80.4 \pm 20.1^{\mathrm{c}}$ & $1.4 \pm 0.2^{\mathrm{b}}$ & $4.2 \pm 1.0^{\mathrm{a}}$ & $225 \pm 54^{\mathrm{a}}$ & $1.9 \pm 0.3^{\mathrm{a}}$ & $102 \pm 16^{\mathrm{a}}$ \\
\hline B (low-AsA) & $54.8 \pm 21.9^{b}$ & $1.3 \pm 0.3^{b}$ & $3.8 \pm 1.2^{\mathrm{a}}$ & $168 \pm 53^{a}$ & $1.8 \pm 0.2^{\mathrm{a}}$ & $80 \pm 11^{\mathrm{a}}$ \\
\hline $\mathrm{C}$ (moderate-AsA) & $27.2 \pm 5.5^{\mathrm{a}}$ & $0.9 \pm 0.1^{\mathrm{a}}$ & $3.6 \pm 0.5^{\mathrm{a}}$ & $208 \pm 29^{a}$ & $1.7 \pm 0.3^{\mathrm{a}}$ & $98 \pm 18^{a}$ \\
\hline $\mathrm{D}($ excess-AsA) & $42.2 \pm 8.6^{\mathrm{b}}$ & $1.2 \pm 0.1^{\mathrm{b}}$ & $3.6 \pm 0.4^{\mathrm{a}}$ & $180 \pm 25^{\mathrm{a}}$ & $1.8 \pm 0.2^{\mathrm{a}}$ & $90 \pm 11^{a}$ \\
\hline
\end{tabular}

Values are $\mathrm{M} \pm \mathrm{SD}(n=5)$. ${ }^{\mathrm{a}, \mathrm{b}, \mathrm{c}}$ Values with different superscript letters in a column are significantly different $(p<0.05)$. The animals fed ascorbic acid (AsA)-deficient diet received AsA by drinking water in the following doses for 22 days: A, AsA 0 $\mathrm{mg} /$ liter; B, AsA $50 \mathrm{mg} /$ liter; C, AsA $500 \mathrm{mg} /$ liter; D, AsA $5,000 \mathrm{mg} /$ liter. PCOOH, phosphatidylcholine hydroperoxide, $\mathrm{PEOOH}$, phosphatidylethanolamine hydroperoxide; PL, phospholipids.

of PCOOH calculated against $10^{5}$ moles of plasma phospholipids in the AsAdeficient animals and in the low-AsA animals showed significantly higher values (1.3-1.5) than that of the moderate-AsA animals (0.9) (Table 4). Liver phospholipid hydroperoxide concentrations showed no change even after the change of AsA intake (Table 4).

The relationship between the $\mathrm{PCOOH}$ concentration and the AsA level in the plasma (Fig. 4-A) showed a high correlation coefficient $(r=0.979)$ with the regression curve of secondary degree, and it revealed that moderate concentration 

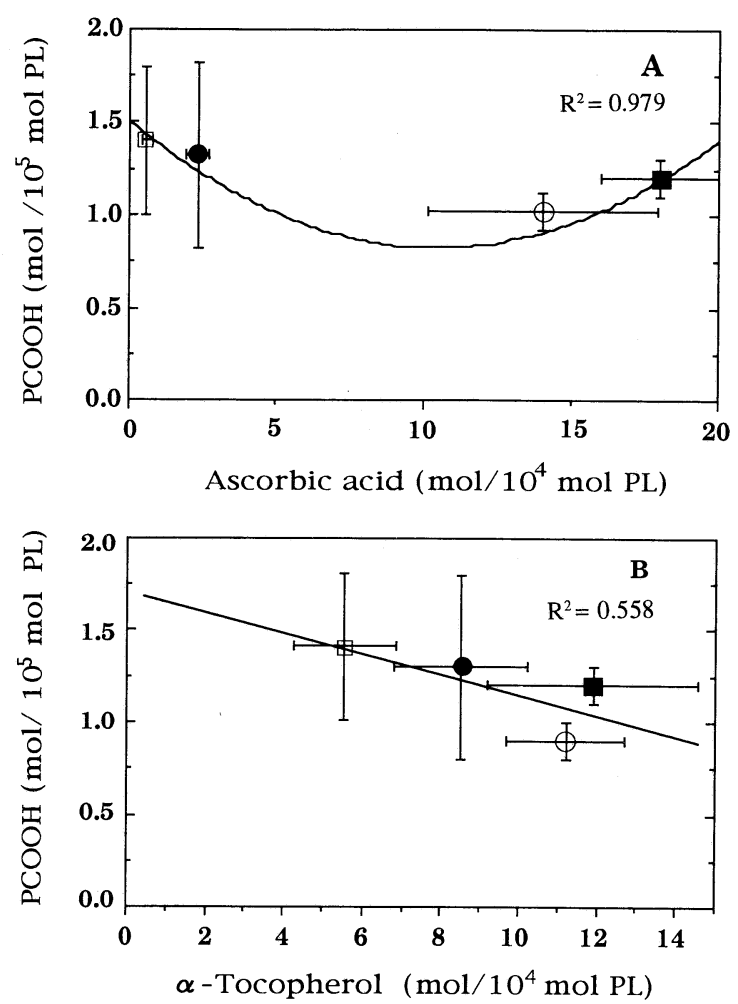

Fig. 4. Relationships of phosphatidylcholine hydroperoxide (PCOOH) against ascorbic acid (A) and $\alpha$-tocopherol (B) in the plasma of guinea pigs given graded doses of ascorbic acid. Abbreviations are the same as those given in Fig. 1 .

of AsA is required in plasma to prevent the increase in PCOOH. To keep the plasma PCOOH as low as 1 mole per $10^{5}$ moles of phospholipids, $50-150$ moles of AsA were required per $10^{5}$ moles of plasma phospholipids. The plasma $\mathrm{PCOOH}$ concentration of excess-AsA animals was significantly higher than that of moderate-AsA animals. A weak correlation $(r=0.558)$ was observed between the molar ratios of $\mathrm{PCOOH}$ and $\alpha$-tocopherol when compared by the units of the number of phospholipid molecules in the plasma (Fig. 4-B).

\section{DISCUSSION}

In the present study, four groups of guinea pigs were given graded doses of AsA were designed to study the effect of AsA supplementation in the diet. Guinea pigs require at least $0.5 \mathrm{mg}$ of AsA/100 $\mathrm{g}$ body weight/ day to prevent scurvy (17). The low-AsA animals (group B; $50 \mathrm{mg}$ of AsA/liter drinking water) prepared in the present study was comparable to $2 \mathrm{mg} \mathrm{AsA} / 100 \mathrm{~g}$ body weight/day. The amount of 
AsA ingested by the moderate-AsA animals (group C; $500 \mathrm{mg}$ AsA/liter drinking water; corresponding to $20 \mathrm{mg}$ AsA/100 g body weight/day) was considered to be optimum for maintaining general health because it was in the range employed in standard commercial diets $(1,000-1,500 \mathrm{mg}$ AsA $/ \mathrm{kg} ; 10-30 \mathrm{mg}$ AsA $/ 100 \mathrm{~g}$ body weight/day) of guinea pigs, which are designed to achieve optimum growth and longevity of this animal species. The excess-AsA animals (group D; 5,000 mg AsA/liter drinking water; corresponding to $200 \mathrm{mg} \mathrm{AsA} / 100 \mathrm{~g}$ body weight/day) was selected in order to examine the effect of AsA overloading (10 times AsA of moderate-AsA animals). No significant difference was observed in the total volume of drinking water consumed which was supplemented with different amounts of AsA.

Supplementation of AsA in the drinking water was effective to increase the plasma AsA level, and the plasma AsA concentration of moderate-AsA animals and of excess-AsA animals was 4-8 times higher than that of AsA-deficient animals and of low-AsA animals (Table 1). The plasma AsA level of the excess-AsA animals was almost the same as that of the moderate-AsA animals. This may be ascribed to the excretion of excess AsA into the urine. In humans, excess AsA is not absorbed from intestine but is excreted into the urine (18).

Hyperlipidemic plasma (characterized as increases of total cholesterol, free cholesterol, triacylglycerol and phospholipids) was most apparent in AsA-deficient animals (group A) (Fig. 2). Marginal intake of AsA also invited increases of plasma free-cholesterol and phospholipids, as shown in the low-AsA animals (group B). Such influence on plasma lipid concentrations might reflect the disturbance of lipid metabolism in AsA-deficient guinea pigs, although the AsA-deficiency did not affect the fatty acid composition of plasma total lipids and of plasma phosphatidylcholine (Tables 1 and 2). Ginter et al. (19) have reported that AsA deficiency in the guinea pig causes an increase in cholesterol in the plasma and in the tissue organelles along with a decrease in the activity of cholesterol- $7 \alpha$-hydroxylase. Ha et al. (20) showed that AsA deficiency results in a decrease in the tissue carnitine level in the guinea pig which blocks the transport of fatty acids into mitochondria, thus shunting triacylglycerol synthesis in the liver. Kotze et al. (21) have suggested that hypertriglyceridemia caused by a deficiency of AsA is associated with the inhibitory effect of AsA on lipoprotein lipase activity.

In the present study, lower AsA intakes as observed in AsA-deficient animals and in low-AsA animals resulted in a decrease in the plasma level of $\alpha$-tocopherol (Table 1). This decrease became more clear when the molecular number of $\alpha$-tocopherol was compared against the number of plasma phospholipid molecules. Hruba et al. (22) demonstrated that the $\alpha$-tocopherol contents in plasma and in other tissues are low in AsA-deficient guinea pigs. Such lower levels of AsA and $\alpha$-tocopherol in the plasma could profoundly influence the plasma lipid peroxide level. As a result, the PCOOH concentration was 3 times higher in AsA-deficient animals and 2 times higher in the low-AsA animals as compared with that of the moderate-AsA animals (Table 4). Such an increase in plasma $\mathrm{PCOOH}$ should 
directly reflect the stimulation of hydroperoxidation of the phospholipid molecules in the plasma lipoproteins. Kimura et al. (23) have reported that osteogenic disorder (ODS) rats lacking the ability to synthesize AsA shows high levels of TBARS in plasma and livers under AsA-deficiency.

The animals which ingested excess AsA (group D) also showed a $\mathrm{PCOOH}$ increase in the plasma (Table 4, Fig. 4). This may reflect the prooxiant effect of excess AsA on phospholipids in plasma lipoprotein particles. Inorganic iron reduced by AsA has been suggested to be an active catalyst of phospholipid peroxidation (7). Generally, iron in plasma is bound to transferrin (24), but in a recent study (25) an alternative low molecular mass species of plasma iron, non-transferrin-bound iron, has been shown to occur in significant concentrations under conditions of transferrin saturation. Randell et al. (26) have reported the effect of AsA on translocation of non-transferrin-bound iron into cells, and they suggested that AsA may reductively mobilize the internal iron store into the regulatory pools. Therefore, we presumed that the PCOOH increase in plasma observed under excess-AsA conditions may be due to AsA-catalyzed phospholipid hydroperoxidation which is possibly accelerated by combination with non-transferrin-bound iron. Previously, Miyazawa et al. (27) observed a significant decrease in $\alpha$-tocopherol in the tissue organelles of guinea pigs treated with an excess-AsA diet. Therefore, the decrease of antioxidative molecules such as $\alpha$-tocopherol under excess AsA conditions, in which $\alpha$-tocopherol may be consumed to scavenge ascorbate radical, may also contribute in the increase in the plasma $\mathrm{PCOOH}$ level.

As liver $\mathrm{PCOOH}$ and phosphatidylethanolamine hydroperoxide (PEOOH) concentrations were not changed even after changing the ingested amount of AsA, hydroperoxidation of phosphatidylcholine in lipoprotein particles should occur in the endothelial cell space and not in the liver.

Recently, oxidative modification of plasma lipoprotein is recognized as one of the most essential reactions in promoting atherogenesis (28). The onset of atherogenesis in aorta has been noted in AsA-deficient guinea pigs (29). Rath and Pauling (30) reported that a high plasma level of lipoprotein(a) is associated with coronary heart disease in humans and that the incidence of cardiovascular disease is decreased by elevating the AsA intake. These studies have suggested that AsA-deficiency especially could increase the incidence of atherogenesis.

The present study clearly demonstrated that the antioxidant function of AsA is important to control the $\mathrm{PCOOH}$ level in plasma and that moderate intake of AsA is required to reveal its optimal antioxidant effect in vivo.

\section{REFERENCES}

1) Bodannes, R.S., and Chan, P. C. (1979): Ascorbic acid as a scavenger of singlet oxygen. FEBS Lett., 105, 195-196.

2) Nishikimi, M. (1975): Oxidation of ascorbic acid with superoxide anion generated by the xanthine-xanthine oxidase system. Biochem. Biophys. Res. Commun., 63, 463-468. 
3) Bielski, B. H., Richter, H. W., and Chan, P. C. (1975): Some properties of the ascorbate free radical. Ann. N.Y. Acad. Sci., 258, 231-237.

4) Packer, J. E., Slater, T. F., and Willson, R. L. (1979): Direct observation of a free radical interaction between vitamin $\mathrm{E}$ and vitamin C. Nature, 278, 737-738.

5) Kunert, K. J., and Tappel, A. L. (1983): The effect of vitamin C on in vivo lipid peroxidation in guinea pigs as measured by pentane and ethane production. Lipids, $\mathbf{1 8}$, 271-274.

6) Chen, L. H., and Chang, M. L. (1978): Effect of dietary vitamin E and vitamin C on respiration and swelling of guinea pig liver mitochondria. J. Nutr., 108, 1616-1620.

7) Miller, D. M., and Aust, S. D. (1989): Studies of ascorbate-dependent, iron-catalyzed lipid peroxidation. Arch. Biochem. Biophys., 271, 113-119.

8) Chen, L. H. (1981): An increase in vitamin $\mathrm{E}$ requirement induced by high supplementation of vitamin C in rats. Am. J. Clin. Nutr., 34, 1036-1041.

9) Miyazawa, T., Fujimoto, K., and Oikawa, S. (1990): Determination of lipid hydroperoxides in low density lipoprotein from human plasma using high performance liquid chromatography with chemiluminescence detection. Biomed. Chromatogr., 4, 131134.

10) Miyazawa, T., Kinoshita, M., Fujimoto, K., Oikawa, S., and Toyota, T. (1993): Distribution of phosphatidylcholine hydroperoxide in hyperlipidemic plasma. Proc. Jpn. Conf. Biochem. Lipids, 35, 243-246 (in Japanese).

11) Ginter, E., Cerna, O., Budlovsky, J., Balaz, V., Hruba, F., Roch, V., and Sasko, E. (1977): Effect of ascorbic acid on plasma cholesterol in humans in a long-term experiment. Int. J. Vitam. Nutr. Res., 47, 123-134.

12) Mayer, F. (1966): Methods of Vitamin Assay, ed. by Association of Official Vitamin Chemists, 3rd ed., Interscience Publ., New York, pp. 317-332.

13) Jannson, L., Nilddon, B., and Lindgren, R. (1978): Quantitation of serum tocopherols by high performance liquid chromatography. J. Chromatogr., 181, 242-245.

14) Kates, M. (1986): Techniques of lipidology, in Laboratory Techniques in Biochemistry and Molecular Biology, ed. by Burdon, R. H., and Knippenberg, P. H., Elsevier, Amsterdam, pp. 186-278.

15) Miyazawa, T., Suzuki, T., Fujimoto, K., and Yasuda, K. (1992): Chemiluminescent simultaneous determination of phosphatidylcholine hydroperoxide and phosphatidylethanolamine hydroperoxide in the liver and brain of the rat. J. Lipid Res., 33, 10511058.

16) Miyazawa, T., Suzuki, T., Fujimoto, K., and Yasuda, K. (1994): Determination of phospholipid hydroperoxides using luminol chemiluminescence-high-performance liquid chromatography. Methods Enzymol., 233, 324-332.

17) Kasai, T., Tsujimura, M., and Fukuda, T. (1982): Synthesis and vitamin C activity of L-threo-hexo-2-enaro-1,4-lactone. Vitamins, 56, 117-131 (in Japanese).

18) Rivers, J. M. (1989): Safety of high-level vitamin C ingestion. Int. J. Vitam. Nutr. Res. Suppl., 30, 95-102.

19) Ginter, E., Nenmec, R., Cerven, J., and Mikus, L. (1973): Quantification of lowered cholesterol oxidation in guinea pigs with latent vitamin $\mathrm{C}$ deficiency. Lipids, 8, 135141.

20) Ha, T. Y., Otsuka, M., and Arakawa, N. (1990): The effect of graded doses of ascorbic acid on the tissue carnitine and plasma lipid concentration. J. Nutr. Sci.

Vol. 42, No. 1, 1996 
Vitaminol., 36, 227-234.

21) Kotze, J. P., Matthews, M. J., and Klerk, W. A. (1974): Effect of ascorbic acid on lipoprotein lipase activities. S. Afr. Med. J., 48, 511-514.

22) Hruba, F., Novakova, V., and Ginter, E. (1982): The effect of chronic marginal vitamin $\mathrm{C}$ deficiency on the $\alpha$-tocopherol content of the organs and plasma of guinea-pigs. Experientia, 38, 1454-1455.

23) Kimura, H., Yamada, Y., Morita, Y., Ikeda, H., and Matsuo, T. (1992): Dietary ascorbic acid depresses plasma and low density lipoprotein lipid peroxidation in genetically scorbutic rats. J. Nutr., 122, 1904-1909.

24) Ichimura, K., and Kihara, H. (1994): Transferrin, structure and cooperativity on metal-binding. Protein Nucleic Acid Enzyme, 39, 2297-2309 (in Japanese).

25) Grootveld, M. C., Bell, J. D., Halliwell, B., Aruoma, O. I., Bomford, A., and Sadler, P. J. (1989): Non-transferrin-bound iron in plasma or serum from patients with idiopathic hemochromatosis. J. Biol. Chem., 264, 4417-4422.

26) Randell, E. W., Parkes, J. G., Olivieri, N. F., and Templeton, D. M. (1994): Uptake of non-transferrin-bound iron by both reductive and nonreductive processes is modulated by intracellular iron. J. Biol. Chem., 269, 16046-16053.

27) Miyazawa, T., Ando, T., and Kaneda, T. (1986): Effect of dietary vitamin C and vitamin E on tissue lipid peroxidation of guinea pigs fed with oxidized oil. Agric. Biol. Chem., 50, 71-78.

28) Parthasarathy, S., and Rankin, S. M. (1992): Role of oxidized low density lipoprotein in atherogenesis. Prog. Lipid Res., 31, 127-143.

29) Novakova, V., Hruba, F., Mrhova, O., Ginter, E., and Masek, J. (1982): The effect of vitamin C deficiency on the aorta of the guinea pig. Atherosclerosis, 43, 139-142.

30) Rath, M., and Pauling, L. (1990): Hypothesis: lipoprotein(a) is a surrogate for ascorbate. Proc. Natl. Acad. Sci. USA, 87, 6204-6207. 